\title{
FORMULATION AND EVALUATION OF LIQUISOLID COMPACTS OF ACECLOFENAC
}

\author{
Bhagya Sree Molli*, G.S.N. Koteswara Rao, B. Nagamani, P. Uma Devi \\ Viswanadha Institute of Pharmaceutical sciences, Visakhapatnam, Andhra Pradesh, India. \\ *Corresponding author e-mail: bhagya.joga@gmail.com
}

\begin{abstract}
:
Aceclofenac is a non-steroidal anti-inflammatory drug (NSAID), prescribed for fever, pain, ankylosing spondylitis and arthritis. According to BCS classification it is a poorly soluble drug and the rate of its oral absorption is often controlled by the dissolution rate in the gastrointestinal tract. There are several techniques to enhance the dissolution of poorly soluble drugs, in which the liquisolid compacts is a promising technique. The objective of present investigation was to develop liquid solid compacts for aceclofenac to improve the dissolution rate. Different formulations were prepared by using Avicel PH 102 as carrier and Aerosil as coating material in different ratios. In-vitro dissolution profiles of the liquisolid formulations were studied and compared with conventional formulation in $\mathrm{pH} 6.8$ phosphate buffer. It was found that liquisolid tablets formulated with PEG 400 and Avicel pH102 produced high dissolution profile and they showed significantly higher drug release rates than conventional tablets due to increase in wetting properties and surface of drug available for dissolution. Drug-excipient interaction studies showed that there is no interaction between the drug and excipients. In conclusion, development of aceclofenac liquisolid tablets is a good approach to enhance the dissolution rate which increases bioavailability.
\end{abstract}

Key words: Liquisolid compacts, dissolution rate, aceclofenac, carrier, coating material

\section{INTRODUCTION:}

Objective: The rate of oral absorption is often controlled by the dissolution rate for poorly soluble and highly permeable (Class II) drugs in the gastrointestinal tract. Therefore, together with the permeability; the solubility and dissolution behavior of a drug are key determinants of its oral rate of bioavailability1. Over the years, various techniques have been employed to enhance the dissolution profile and, in turn, the absorption efficiency and bioavailability of water-insoluble salts and polymorphic forms, the formation of water-soluble molecular complexes, drug micronization, solid dispersion, co-precipitation, lyophilization, microencapsulation, and inclusion of drug solutions or liquid drugs into soft gelatin capsules are some of the major formulation tools which have been shown to enhance the dissolution characteristics of water-insoluble drugs, however, among them, the technique of "liquisolid compacts" is one of the most promising techniques².

Formulating liquid medications into solid compacts has been the object of many studies. The liquisolid compacts are acceptably flowing and compressible powdered forms of liquid medications. The term "liquid medication" implies the oily liquid drugs and solutions or the suspensions of water insoluble solid drugs carried in suitable nonvolatile solvent systems termed the liquid vehicles ${ }^{3}$. Using this formulation technique, a liquid medication may be converted into a dry-looking, non-adherent, free flowing and 
readily compressible powder through a simple blending with selected powder excipients referred to as the carrier and coating materials ${ }^{4}$.

Hence, the objective of the present work was to formulate the liquid solid compacts for aceclofenac to improve the solubility and dissolution rate, which can increase clinical efficacy or reduce the oral dosage required to achieve the same effect.

\section{MATERIALS AND METHODS}

\section{Materials}

Aceclofenac, Aerosil and Avicel were purchased from Yarrow Chem Products. Propylene glycol was purchased from Ranbaxy, and sodium starch glycolate from Oxford laboratories.

\subsection{Solubility Studies}

Solubility studies were performed for the selection of best non-volatile solvents. The pure drug was dissolved in two different nonvolatile solvents (propylene glycol and polyethylene glycol 400) and distilled water. An excess amount of pure drug was added to the above solvents and then stirred with magnetic stirrer and centrifuged at $3000 \mathrm{rpm}$ for about 15 minutes and the supernatant was collected and analyzed with UV spectrophotometer 5 .

\subsection{Determination of flowable liquid retention potential $(\varnothing)$ :}

It is defined as the maximum weight of liquid that can be retained per unit weight of powder material in order to produce an acceptably flowing liquid/powder admixture. This $\emptyset$-value of powders may be determined using a new procedure, the liquisolidflowability (LSF) test. The $\emptyset$-value was used to calculate excipients quantities.
Equation for this is as follows:

$$
\mathrm{L}_{\mathrm{f}}=\Phi+\varphi(1 / \mathrm{R})
$$

Where $\Phi$ and $\varphi$ are the constant $\emptyset$ values of carrier and coating materials, respectively.

$L_{f}$ can be calculated from the linear relationship of $L_{f}$ vs. 1/R.

$$
\mathrm{L}_{\mathrm{f}}=(1 / \mathrm{R}) \text { eq. }
$$

The $\phi$-values were plotted graphically against the corresponding angle of slide which represented the flowable liquid retention potential of Aerosil.

According to Tayel et. al., in propylene glycol, the $\phi$-value is 0.16 for Avicel PH 102 and 1.5 for Aerosil 200 and for PEG 400; the $\phi$-value is 0.005 for Avicel PH 102 and 3.26 for Aerosil 200. The liquid load factor for PG and PEG 400 liquisolid system was calculated from flowable liquid retention potential using $R$ value (excipient ratio) of 20 , which is as follows

$$
\begin{gathered}
L_{\mathrm{f}}=\Phi+\varphi(1 / \mathrm{R}) \\
L_{\mathrm{f}}=0.16+1.5(1 / 20)=0.235 \\
L_{\mathrm{f}}=0.005+1.5(1 / 20)=0.168
\end{gathered}
$$

$\mathrm{R}$ represents the ratio between the weights of carrier (Q) and coating (q) materials present in the formulation ${ }^{6}$.

$$
\mathrm{R}=\mathrm{Q} / \mathrm{q}
$$

An acceptably flowing and compressible liquisolid system can be prepared only if a maximum liquid on the carrier material is not exceeded; such a characteristic amount of liquid is termed the liquid load factor $\left(\mathrm{L}_{\mathrm{f}}\right)$ and defined as the ratio of the weight of liquid medication (W) over the weight of the carrier powder (Q) in the system, which should be possessed by an acceptably flowing and compressible liquisolid system. i.e.

$$
\mathrm{L}_{\mathrm{f}}=\mathrm{W} / \mathrm{Q}
$$

Therefore, according to the ratio of the carrier/ coat materials $(R), L_{f}$ can be calculated from the linear relationship of $\mathrm{L}_{\mathrm{f}}$ versus $1 / R$. Next, according to the used liquid vehicle concentration, different weights of the liquid drug solution (W) will be used. So, by knowing both $\mathrm{L}_{\mathrm{f}}$ and $\mathrm{W}$, the appropriate quantities of carrier (Q) and coating (q) 
powder materials required to convert a given amount of liquid medication (W) into an acceptably flowing and compressible liquisolid system, could be calculated from equations (1) and (2) ${ }^{7}$.

\subsection{Formulation of liquisolid tablets:}

For the preparation of liquisolid compacts of aceclofenac, a non-volatile solvent is chosen for dissolving the drug. From the results of solubility studies and evaluation of flow properties, propylene glycol as the liquid medicament, MCC (Avicel PH 102) as carrier and colloidal silica (Aerosil 200) as the coating material were selected for the preparation of liquisolid compacts. Various ratios of carrier to coating material were selected and different ratios of drug: solvent were selected. According to desired quantities, drug and propylene gylcol were accurately weighed in a beaker and then stirred constantly, until a homogenous mixture was obtained. Selected amounts (W) of the resultant liquid medication were incorporated into calculated quantities of carrier contained in a mortar. The formulae are given in table no.1.

\section{Mixing:}

The mixing procedure was conducted in three stages.

Stage-1: During the first stage, the system was blended with carrier at an approximate mixing rate of one rotation/sec for approximately one minute for even distribution of the liquid medication into the powder.

Stage-2: In the second mixing stage, calculated quantities of coating material was added to the system and blended for $2 \mathrm{~min}$. The liquid/powder admixture was evenly spread as a uniform layer on the surfaces of the mortar and left standing for approximately $5 \mathrm{~min}$ to allow the drug solution to be absorbed in interior of the powder particles.

Stage-3: In the third stage, the powder was scraped off from the mortar surfaces by means of aluminum spatula, then producing the final liquisolid formulation to be compressed.

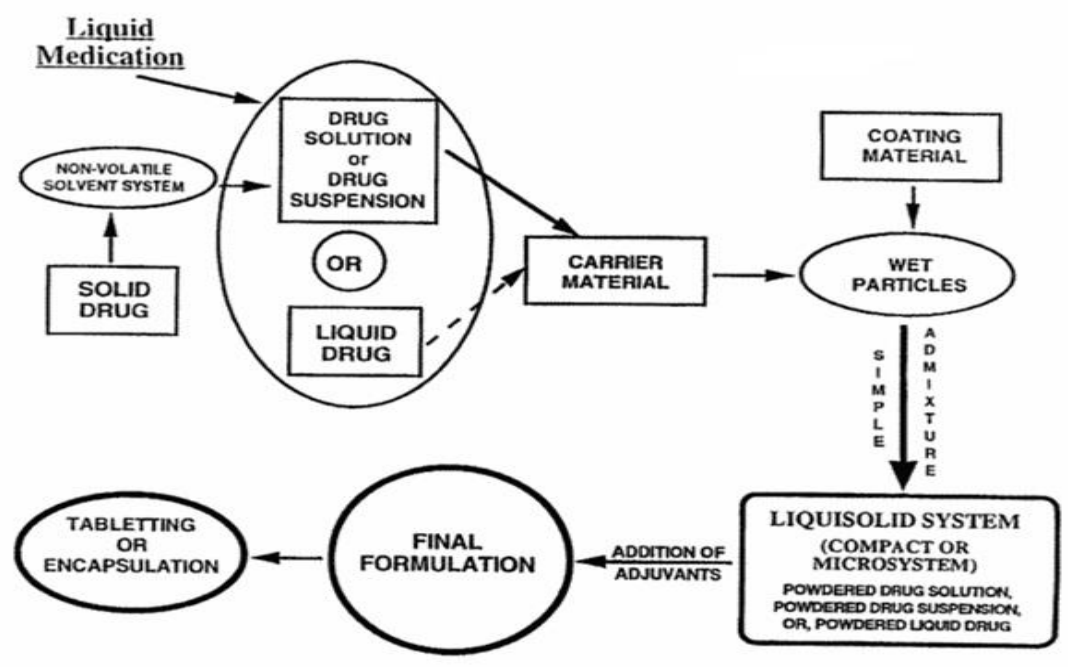

Fig. 1: Liquisolid compacts preparation 
Table 1: Formulae forliquisolid compact tablets of aceclofenac

\begin{tabular}{|c|c|c|c|c|c|c|c|c|}
\hline $\begin{array}{c}\text { Formulation } \\
\text { code }\end{array}$ & $\begin{array}{l}\text { Drug conc. } \\
\text { in PG }\end{array}$ & $R=Q / q$ & $\mathbf{W}$ & $\begin{array}{c}\text { Loading } \\
\text { factor }\left(L_{f}\right)\end{array}$ & $\begin{array}{c}\text { Avicel } \\
\text { (Q) }\end{array}$ & $\operatorname{Aerosil}(q)$ & $\begin{array}{c}\text { SSG } \\
(\sim 5 \%)\end{array}$ & $\begin{array}{c}\text { Unit } \\
\text { dose(mg) }\end{array}$ \\
\hline F1 & $40 \%$ & 5 & 250 & 0.822 & 304.13 & 60.82 & 32.05 & 647 \\
\hline $\mathrm{F} 2$ & $40 \%$ & 10 & 250 & 0.491 & 509.16 & 50.91 & 39.93 & 850 \\
\hline F3 & $40 \%$ & 15 & 250 & 0.38 & 657.89 & 43.85 & 50.26 & 1002 \\
\hline F4 & $40 \%$ & 20 & 250 & 0.325 & 769.23 & 38.46 & 55.31 & 1113 \\
\hline F5 & $50 \%$ & 5 & 200 & 0.822 & 243.3 & 48.66 & 26.04 & 518 \\
\hline F6 & $50 \%$ & 10 & 200 & 0.491 & 407.33 & 40.73 & 33.94 & 682 \\
\hline F7 & $50 \%$ & 15 & 200 & 0.38 & 526.31 & 35.08 & 39.61 & 801 \\
\hline F8 & $50 \%$ & 20 & 200 & 0.325 & 615.38 & 30.76 & 44.86 & 891 \\
\hline F9 & $60 \%$ & 5 & 167 & 0.822 & 203.16 & 40.63 & 21.21 & 432 \\
\hline F10 & $60 \%$ & 10 & 167 & 0.491 & 340.12 & 34.01 & 28.87 & 570 \\
\hline F11 & $60 \%$ & 15 & 167 & 0.38 & 439.47 & 29.29 & 33.24 & 669 \\
\hline $\mathrm{F} 12$ & $60 \%$ & 20 & 167 & 0.325 & 513.84 & 25.69 & 37.47 & 744 \\
\hline
\end{tabular}

Table 2: Formula for immediate release tablets of aceclofenac

\begin{tabular}{cc}
\hline Ingredient & C1 \\
\hline Aceclofenac & 100 \\
Lactose & 170 \\
MCC PH102 & 100 \\
Sodium starch glycolate $5 \%)$ & 20 \\
Magnesium stearate & 10 \\
Total & $\mathbf{4 0 0}$ \\
\hline
\end{tabular}

\subsection{Pre-compression properties:}

All the liquisolid formulations were evaluated for angle of repose, bulk density, tapped density, Carr's index and Hausner's ratio.

\section{Angle of Repose:}

The angle of repose of powder mixtures of liquisolid compacts were determined by fixed funnel method. The accurately weighed powder mixture of liquisolid compact was taken in a funnel. The height of the funnel was adjusted to such that the apex of the heap of the powder just touched the funnel tip. The powder was allowed to flow through the funnel freely onto the surface of graph sheet. The height and diameter of the powder cone was measured and the angle of repose was calculated using the below formula.

$$
\begin{gathered}
\operatorname{Tan} \theta=h / r \\
\theta=\tan ^{-1}(h / r)
\end{gathered}
$$

Where, $\theta$ is the angle of repose,

$\mathrm{h}$ is the height in $\mathrm{cm}$ and $r$ is the radius in $\mathrm{cm}$.

\section{Bulk Density:}

Bulk density of powder mixture was determined using graduated cylinder. The volume occupied by the sample was recorded. Bulk density is calculated using the formula:

Bulk density, $\rho_{b}=M / V_{b}$

Where, $M$ is the weight of sample, $V_{b}$ is the volume of sample.

Tapped Density:

Tapped density of all types of powder mixture was determined by using the below formula. The cylinder with powder mixture was tapped from height of 2 inches until a constant volume is obtained. Volume occupied by the sample after tapping was recorded and tapped density was calculated using the formula

\section{Tapped density, $\rho_{t}=M / V_{t}$}

Where, $\mathrm{M}$ is the weight of sample, $\mathrm{V}_{\mathrm{t}}$ is tapped volume of sample. 


\section{Carr's Index (\%):}

The compressibility index has been proposed as an indirect measure of bulk density, size and shape, surface area, moisture content and cohesiveness of material because all of these can influence the observed compressibility index. The simplest way for measurement of free flow of powder is Carr's index, an indication of the ease with which a material can be induced to flow. Carr's index (CI) was calculated using the below formula:

$$
\text { Carr's index }(\%)=
$$

[(Tapped density - Bulk density)/Tapped density] x 100

\section{Hausner's Ratio:}

Hausner's ratio is an indirect index of ease of powder flow. It is calculated by the following formula.

\section{Hausner's Ratio= Tapped density $\left(\rho_{\mathrm{t}}\right) /$ Bulk density $\left(\rho_{b}\right)$}

Where $\rho_{\mathrm{t}}$ is tapped density and $\rho_{\mathrm{b}}$ is bulk density.

\section{flowability}

Lower Hausner's ratio $(<1.25)$ - Better Higher Hausner's ratio $(>1.25)$ - Poor flowability

\subsection{Evaluation of Liquisolid Tablets:}

The prepared liquisolid tablets were evaluated for weight variation, content uniformity, hardness, friability, and disintegration time. Hardness was determined by Pfizer hardness tester and friability by digital tablet friability tester. The disintegration time was measured using USP disintegration tester (Electrolab ETC 11L). Flow properties were measured in terms of angle of repose. All the studies were done in triplicate.

\section{Weight variation test:}

The weight variation test was performed by randomly selecting twenty tablets from each formulation. The selected tablets were weighed individually. The average weight and weight variation were calculated as described in I.P.

$$
\begin{gathered}
\% \text { Weight variation }=[\text { [Individual } \\
\text { weight - Average weight }) / \text { Average weight }] \\
\text { x } 100
\end{gathered}
$$

Table 3: Limits for weight variation test as per I.P.

Tablet weight $\%$ deviation allowed

\begin{tabular}{cc}
\hline$<80$ & $\pm 10 \%$ \\
$80-250$ & $\pm 7.5 \%$ \\
$>250$ & $\pm 5 \%$ \\
\hline
\end{tabular}

\section{Drug content:}

A Random sample of five tablets was selected and crushed, from this a weight the equivalent to $100 \mathrm{mg}$ of drug was weighed accurately and transferred to a $100 \mathrm{ml}$ volumetric flask containing a small volume of methanol. The solution was made up to the mark with phosphate buffer pH7.4. The sample was diluted up to a concentration of $10 \mu \mathrm{g} / \mathrm{ml}$ and analyzed for drug content at $275 \mathrm{~nm}$ spectrophotometrically.

\section{Hardness:}

The hardness of formulated liquisolid tablets was assessed using a Monsanto hardness tester and the mean hardness of three tablets was determined.

Limit: $4-7 \mathrm{~kg} / \mathrm{cm}^{2}$

\section{Friability:}

The Roche friability test apparatus was used to determine the friability of the tablets. 20 tablets were weighed and placed in the apparatus, and allowed to operate for 100 revolutions at a rate of $25 \mathrm{rpm}$. The tablets were collected, dedusted and reweighed. The percentage of the friability was calculated.

Percentage friability $=[($ Initial weight

- Final weight)/Initial weight)] x 100 


\section{Disintegration test:}

The disintegration test was carried out using disintegration test apparatus as specified in the Indian Pharmacopoeia which consists of a basket rack holding 6 plastic tubes, opened at the top and covered at the bottom by a 10 mesh screen. Tablets were placed in the tubes of basket rack assembly and were immersed in $900 \mathrm{ml}$ of water kept in 1 liter beaker held at $37^{\circ} \pm 2^{\circ} \mathrm{C}$. The apparatus was operated at a rate of 28 to 32 cycles per minute and the time taken by the tablets to disintegrate was noted ${ }^{9}$.

Table 4: Time limit for disintegration of different types of tablets as per I.P.

\begin{tabular}{cc}
\hline Type of tablet & Time (min) \\
\hline Uncoated & $<15$ \\
Film coated & $<30$ \\
Sugar coated & $<60$ \\
\hline
\end{tabular}

\section{In-vitro dissolution studies:}

The in-vitro drug release profiles of aceclofenac from liquisolid compacts and directly compressed tablets were obtained using a dissolution rate test apparatus USP type-II paddle (Electro lab ETC 11L) at a temperature of $37 \pm 2^{\circ} \mathrm{C}$.

The withdrawn samples were filtered and analyzed spectrophotometrically at $275 \mathrm{~nm}$.
The mean of three determinations was used to calculate the drug release from each of the formulations ${ }^{10}$.

Comparative dissolution studies were done for prepared liquisolid compact tablet formulations (F1-F12), prepared immediate release tablets (C1), and procured marketed tablets (M1) and pure drug (P1).

Marketed Tablets (M1):

Conventional Aceclofenac tablets were procured from market and conduct dissolution studies similar to the prepared formulations and immediate release tablets.

Name: Acemize ${ }^{\circledR}$

Manufacturer: Akum Drugs and Pharmaceuticals Ltd.

Description: Each tablet contains $100 \mathrm{mg}$ of Aceclofenac IP

Colour: Sunset yellow FCF

Batch No.022F4AEL

Expiry Date: 05/2016.

\section{RESULTS AND DISCUSSION}

\section{Solubility studies}

The solubility data of drug Aceclofenac was studied in various solvents. Aceclofenac appears to be more soluble in propylene glycol than in other vehicles. The solubility is an important factor in liquid solid systems, as higher solubility of drug in liquid vehicle can lead to higher dissolution rates.

Table 5: Solubility of Aceclofenac in various solvents

\begin{tabular}{cc}
\hline Solvent & Solubility $(\mathbf{m g} / \mathbf{m l})$ \\
\hline Poly ethylene glycol- 400 & 14.62 \\
Propylene glycol & 22.4 \\
Distilled water & 0.015 \\
\hline
\end{tabular}


Table 6: Pre-compression studies results

\begin{tabular}{cccccc}
\hline $\begin{array}{c}\text { Formulation } \\
\text { code }\end{array}$ & $\begin{array}{c}\text { Angle of } \\
\text { Repose }\end{array}$ & $\begin{array}{c}\text { Hausner's } \\
\text { ratio }\end{array}$ & Carr's index & Bulk density & $\begin{array}{c}\text { Tapped } \\
\text { density }\end{array}$ \\
\hline F1 & $15.02 \pm 0.05$ & 1.17 & 13.26 & $0.373 \pm 0.10$ & $0.430 \pm 0.01$ \\
F2 & $14.03 \pm 0.04$ & 1.12 & 12.45 & $0.394 \pm 0.10$ & $0.450 \pm 0.03$ \\
F3 & $18.03 \pm 0.03$ & 1.15 & 14.22 & $0.391 \pm 0.07$ & $0.462 \pm 0.12$ \\
F4 & $15.90 \pm 0.07$ & 1.18 & 11.59 & $0.389 \pm 0.11$ & $0.440 \pm 0.08$ \\
F5 & $19.18 \pm 0.06$ & 1.16 & 15.27 & $0.495 \pm 0.09$ & $0.587 \pm 0.11$ \\
F6 & $27.11 \pm 0.01$ & 1.11 & 11.85 & $0.410 \pm 0.05$ & $0.465 \pm 0.06$ \\
F7 & $25.68 \pm 0.04$ & 1.14 & 13.34 & $0.390 \pm 0.02$ & $0.450 \pm 0.04$ \\
F8 & $23.52 \pm 0.03$ & 1.15 & 12.58 & $0.389 \pm 0.02$ & $0.445 \pm 0.03$ \\
F9 & $15.90 \pm 0.08$ & 1.17 & 11.92 & $0.495 \pm 0.01$ & $0.562 \pm 0.05$ \\
F10 & $19.19 \pm 0.02$ & 1.13 & 12.06 & $0.401 \pm 0.04$ & $0.456 \pm 0.05$ \\
F11 & $17.21 \pm 0.03$ & 1.14 & 16.38 & $0.398 \pm 0.07$ & $0.476 \pm 0.01$ \\
F12 & $25.50 \pm 0.04$ & 1.10 & 11.01 & $0.396 \pm 0.08$ & $0.445 \pm 0.03$ \\
\hline
\end{tabular}

Table 7: In-vitro evaluation tests of liquisolid compact tablets and conventional tablets

\begin{tabular}{ccccc}
\hline $\begin{array}{c}\text { Formulation } \\
\text { code }\end{array}$ & $\begin{array}{c}\text { Weight } \\
\text { variation }\end{array}$ & $\begin{array}{c}\text { Hardness } \\
\left(\mathbf{k g} / \mathbf{c m}^{2}\right)\end{array}$ & $\begin{array}{c}\text { Friability } \\
\text { (\%) }\end{array}$ & $\begin{array}{c}\text { Disintegration } \\
\text { Time(sec) }\end{array}$ \\
\hline F1 & $620 \pm 4.4$ & $4.8 \pm 1.2$ & $0.23 \pm 0.05$ & 45 \\
F2 & $825 \pm 1.5$ & $4.2 \pm 1.1$ & $0.21 \pm 0.06$ & 58 \\
F3 & $950 \pm 2.5$ & $5.6 \pm 0.6$ & $0.20 \pm 0.05$ & 49 \\
F4 & $1090 \pm 3.1$ & $4.3 \pm 1.4$ & $0.17 \pm 0.04$ & 55 \\
F5 & $530 \pm 3.7$ & $4.9 \pm 0.8$ & $0.19 \pm 0.03$ & 47 \\
F6 & $658 \pm 4.2$ & $4.3 \pm 0.5$ & $0.20 \pm 0.08$ & 51 \\
F7 & $800 \pm 3.3$ & $4.9 \pm 0.3$ & $0.23 \pm 0.05$ & 59 \\
F8 & $875 \pm 6.3$ & $5.7 \pm 0.4$ & $0.21 \pm 0.06$ & 48 \\
F9 & $465 \pm 4.9$ & $5.5 \pm 0.6$ & $0.20 \pm 0.05$ & 52 \\
F10 & $595 \pm 2.7$ & $5.1 \pm 0.2$ & $0.24 \pm 0.03$ & 59 \\
F11 & $680 \pm 4.1$ & $5.7 \pm 0.3$ & $0.18 \pm 0.05$ & 60 \\
F12 & $760 \pm 2.1$ & $5.1 \pm 1.2$ & $0.25 \pm 0.02$ & 53 \\
\hline
\end{tabular}


In-vitro dissolution studies

Table 8: In-vitro dissolution profile of Pure drug (P1), Marketed product (M1) and Rapid Disintegrating Tablet (R1)

\begin{tabular}{ccccc}
\hline S.No. & Time (min) & $\begin{array}{c}\text { Pure Drug } \\
\text { (P1) }\end{array}$ & $\begin{array}{c}\text { Marketed } \\
\text { Product (M1) }\end{array}$ & $\begin{array}{c}\text { Rapid } \\
\text { Disintegrating } \\
\text { Tablet (R1) }\end{array}$ \\
\hline 1 & 0 & 0.00 & 0 & 0 \\
2 & 5 & 5.14 & 15.39 & 13.65 \\
3 & 10 & 8.74 & 22.35 & 24.39 \\
4 & 15 & 14.91 & 28.74 & 31.06 \\
5 & 20 & 16.97 & 34.26 & 41.81 \\
6 & 30 & 22.63 & 44.42 & 49.35 \\
7 & 40 & 24.69 & 54.87 & 64.45 \\
8 & 50 & 28.29 & 60.97 & 72.00 \\
9 & 60 & 39.60 & 69.68 & 76.06 \\
\hline
\end{tabular}

Table 9: In-vitro dissolution profile of liquisolid compact tablets of Aceclofenac, F1-F6

\begin{tabular}{cccccccc}
\hline S.No. Time (min) & F1 & F2 & F3 & F4 & F5 & F6 \\
\hline 1 & 0 & 0 & 0 & 0 & 0 & 0 & 0 \\
2 & 5 & 20.03 & 22.41 & 18.13 & 28.39 & 20.67 & 21.81 \\
3 & 10 & 27.82 & 29.38 & 25.55 & 39.52 & 26.15 & 25.55 \\
4 & 15 & 38.13 & 35.69 & 33.26 & 49.01 & 33.48 & 32.16 \\
5 & 20 & 43.55 & 49.35 & 54.81 & 59.26 & 41.26 & 41.23 \\
6 & 30 & 57.96 & 56.97 & 63.24 & 67.49 & 50.33 & 51.68 \\
7 & 40 & 63.51 & 62.14 & 75.42 & 72.83 & 67.84 & 60.71 \\
8 & 50 & 79.35 & 77.59 & 82.05 & 87.72 & 78.45 & 72.13 \\
9 & 60 & 84.00 & 87.00 & 90.00 & 95.30 & 82.00 & 86.00 \\
\hline
\end{tabular}


Table 10: In-vitro dissolution profile of liquisolid compact tablets of aceclofenac, F7-F12

\begin{tabular}{cccccccc}
\hline S.No. & Time (min) & F7 & F8 & F9 & F10 & F11 & F12 \\
\hline 1 & 0 & 0 & 0 & 0 & 0 & 0 & 0 \\
2 & 5 & 23.48 & 25.87 & 22.81 & 23.63 & 20.96 & 25.61 \\
3 & 10 & 29.52 & 31.94 & 30.86 & 31.87 & 29.97 & 32.25 \\
4 & 15 & 36.68 & 39.81 & 39.25 & 39.54 & 38.54 & 40.27 \\
5 & 20 & 49.74 & 46.74 & 46.39 & 48.14 & 46.31 & 51.18 \\
6 & 30 & 58.17 & 59.67 & 51.74 & 59.43 & 54.19 & 59.78 \\
7 & 40 & 67.83 & 68.58 & 59.39 & 67.35 & 66.51 & 68.31 \\
8 & 50 & 78.26 & 79.35 & 66.74 & 76.91 & 74.37 & 77.98 \\
9 & 60 & 88.00 & 91.06 & 79.00 & 81.00 & 84.00 & 88.00 \\
\hline
\end{tabular}

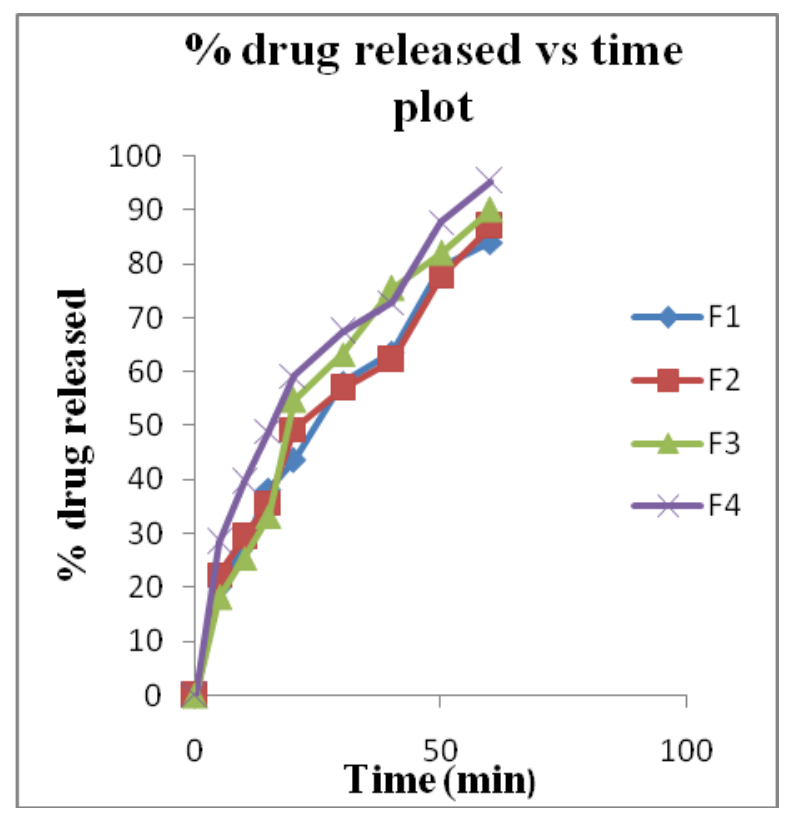

Fig. 2: \% drug released vs. time plot of formulations, F1-F4

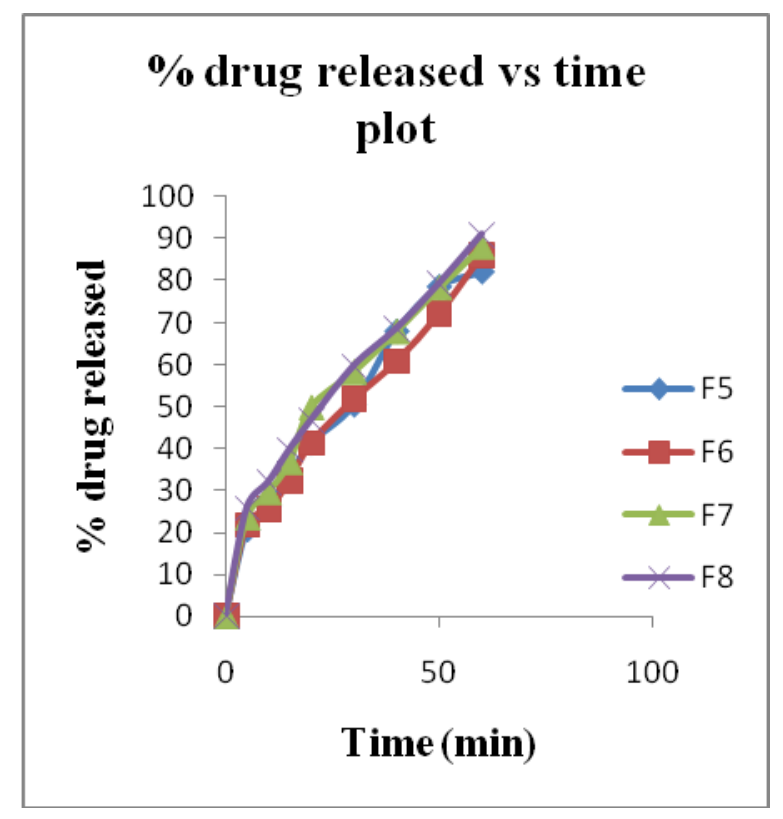

Fig. 3: \% drug released vs. time plot of of formulations, F5-F8 


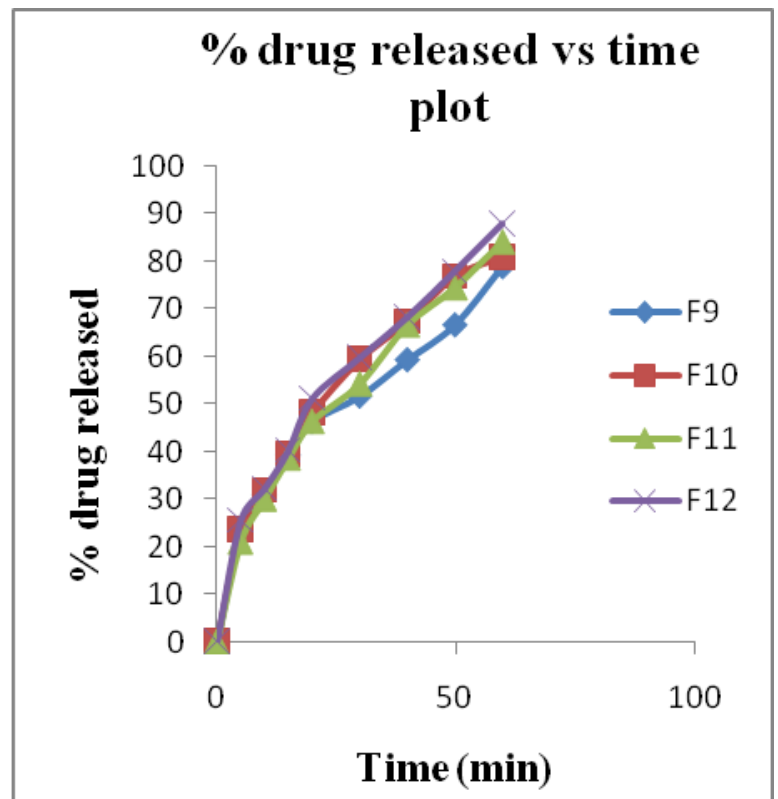

Fig. 4: \% drug released vs. time plot of formulations, of formulations, F9-F12

\section{FTIR Spectroscopy:}

FTIR studies help to determine the any chemical interaction between drug and

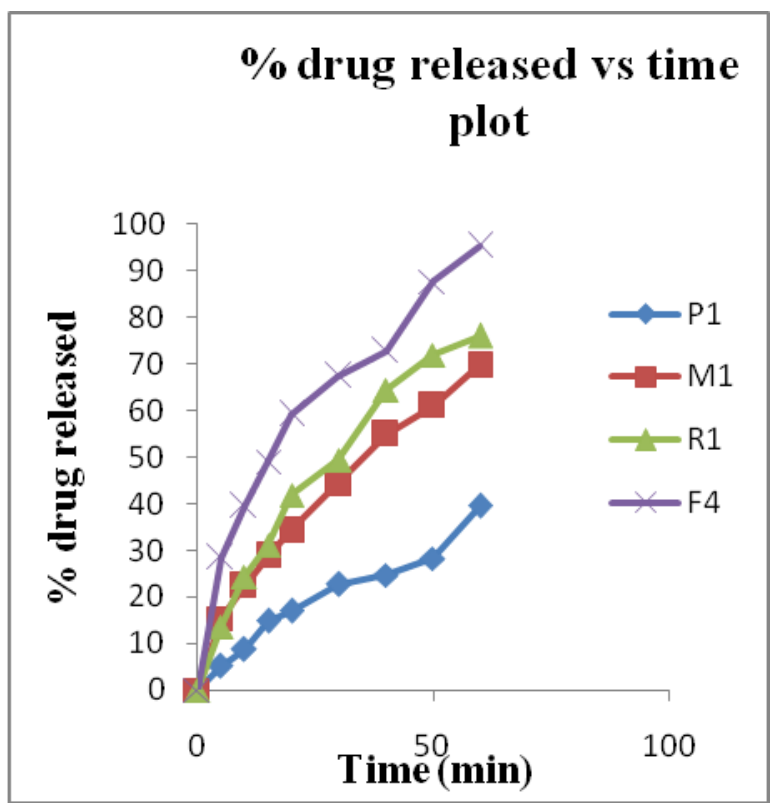

Fig. 5: \% drug released vs. time plot of formulations, P1, M1, R1 and F4

excipients used in the formulation. The FTIR spectra of drug, Avicel PH102, Aerosil, physical mixture, and LSC formulation were recorded.

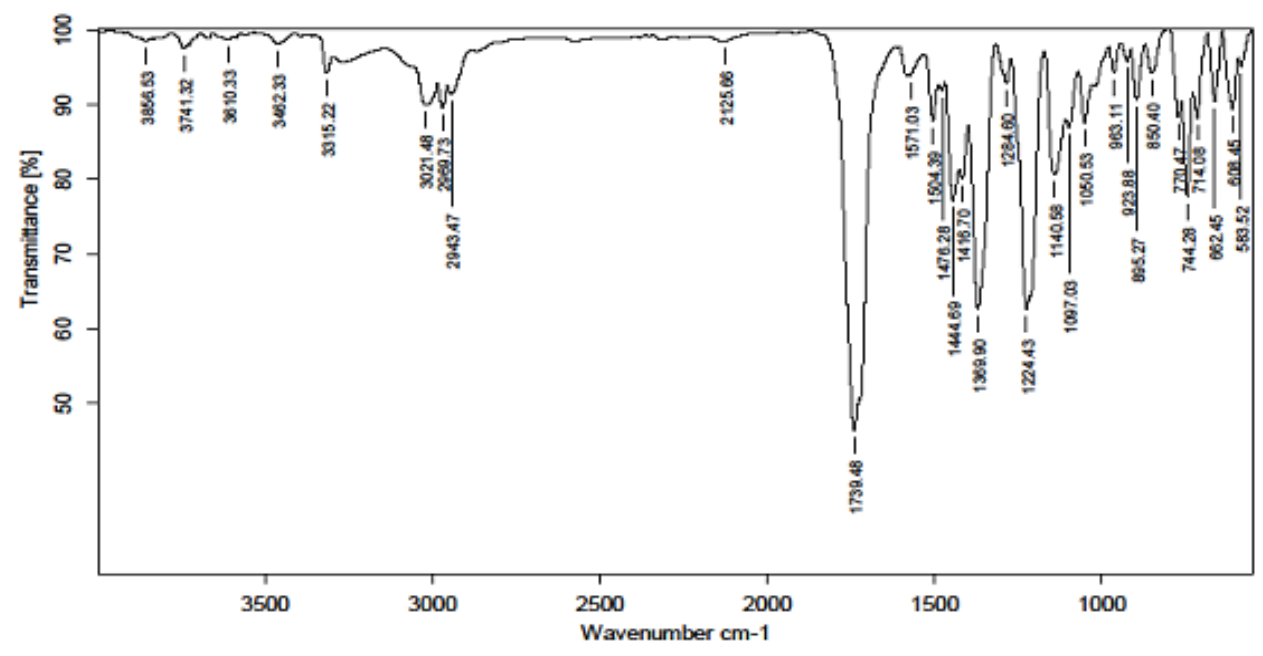

Fig. 6: FTIR spectra of Aceclofenac 


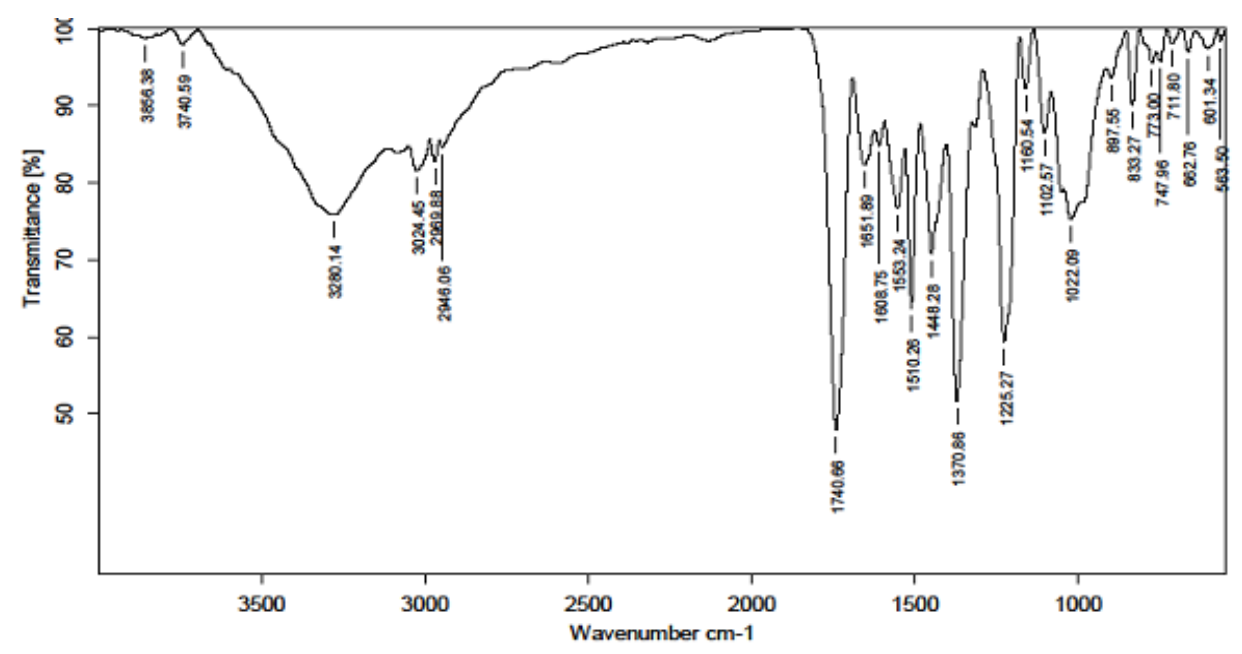

Fig. 7: FTIR spectra of AVICEL pH 102

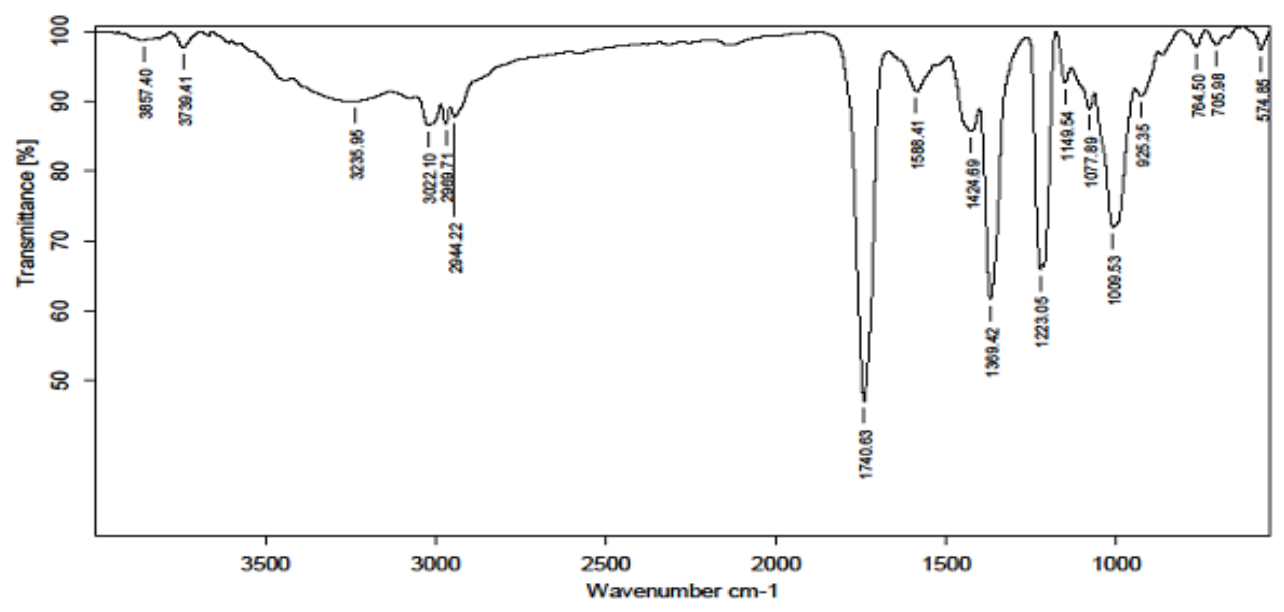

Fig. 8: FTIR spectra of Sodium starch glycolate

All the formulations have shown preformulation tests results within the limits and also passed the post-compression parameters (within the limits). FTIR studies revealed that there are no incompatibilities among the ingredients used in formulation.

Based on the in-vitro dissolution studies, it was found that the pure drug has shown $39.6 \%$ drug release in $60 \mathrm{~min}$ where as marketed product and prepared rapid disintegration tablet shown 69.68 and 76.06 respectively in $60 \mathrm{~min}$.
Formulations, F1 to F4 containing 40\% drug concentration in propylene glycol shown 84.00, 87.00, 90.00 and $95.30 \%$ drug release respectively in $60 \mathrm{~min}$. and F4 with high carrier to coating ratio has shown high drug release of $95.03 \%$ in $60 \mathrm{~min}$.

Formulations, F5 to F8 containing 50\% drug concentration in propylene glycol shown 82.00, 86.00, 88.00 and $91.06 \%$ drug release respectively in $60 \mathrm{~min}$. and F8 with high carrier to coating ratio has shown high drug release of $91.06 \%$ in $60 \mathrm{~min}$.

Formulations, F9 to F12 containing 60\% drug concentration in propylene glycol shown 
79.00, 81.00, 84.00 and 88.00\%drug release respectively in $60 \mathrm{~min}$. and F12 with high carrier to coating ratio has shown high drug release of $88 \%$ in $60 \mathrm{~min}$.

From the above observations it was clear that the formulations with low concentration of drug (40\%) in propylene glycol (that means high concentration of propylene glycol) have shown high \% drug release. In addition to this it was also found that the formulations with high carrier content have shown high \% drug release.

Among all the formulations, it was found that the formulation, F4 containing 40\% drug concentration in propylene glycol and ' $R$ ' value of 20 (carrier to coating ratio) has shown highest drug release of $95.03 \%$ in 60 min. On comparison with pure drug, marketed product and prepared rapid disintegration tablet; the drug release shown by the formulation, F4 was relatively high.

Hence, formulation, F4 was considered as optimized formulation.

Since the liquisolid compacts contain a solution of the drug in non-volatile vehicle used for the preparation of the liquisolid compacts, the drug surface available for the dissolution is tremendously increased along with increased wettability. In essence, after disintegration, the liquisolid primary

\section{REFERENCES}

1. K. H. Edward and D. Li, "Solubility," in Drug like Properties: Concept, Structure, Design and Methods, from ADME to Toxicity Optimization, Academic Press, Elsevier, 58, 2009.

2. A. Martin, Physical Pharmacy, Willaims and Wilkins, Baltimore, Md, USA, $4^{\text {th }}$ edition, 1993.

3. Finholt P, Solvang S. Dissolution kinetics of drugs in human gastric juice, the rule of surface tension. J. Pharm. Sci. 57; 1322-1326, 1968

4. Javadzadeh Y, Siahi-Shadbad MR, BarzegarJalali M, Nokhodchi A. Enhancement of particles dispersed in the dissolution medium contain the drug in a molecularly dispersed state supporting the enhanced dissolution rate. Therefore, the significantly increased surface area of the molecularly dispersed Aceclofenac in the liquisolid compacts may be principally responsible for their higher dissolution rates.

\section{CONCLUSION}

Based on the present investigation, it was concluded that the liquisolid technique can be successfully used to enhance the dissolution rate of Aceclofenac, which is a poorly soluble drug. Liquisolid compact tablets of Aceclofenac can be best formulated using propylene glycol as non-volatile solvent with $40 \%$ drug concentration, Avicel as carrier material and Aerosil as coating material with ' $\mathrm{R}$ ' value of 20 (carrier to coating ratio).

So as a pharmacist we preferred generic drugs than branded forms as they are cost effective and equally active as branded ones.

\section{ACKNOWLEDGEMENT}

The authors are thankful to the management, principal and faculty of Viswanadha Institute of Pharmaceutical Sciences for rendering their assistance in this work.

dissolution rate of piroxicam using liquisolid compacts. Farmaco. 60:361-365, 2005.

5. Rudnic EM and Kottke MK. Tablet dosage forms, In: Banker GS, Rhodes CT. Modern Pharmaceutics, $4^{\text {th }}$ Ed., New York, Marcel Dekker Inc., 333-394; 2002.

6. Liqui solid systems and methods of preparing same

7. V. J.Kapure, V. V. Pande, and P.K.Deshmukh.Dissolution Enhancement of Rosuvastatin Calcium by Liquisolid Compact Technique.Journal of Pharmaceutics, Article ID 315902, 1-9,2013. 
8. Indian Pharmacopoeia, Ministry of Health and family welfare, Government of India, Published by the controller of publications, Delhi.Vol. II;A-81,1996.

9. Gudikandula R, Madhavi K, Thakkalapally SR, Veeramalla A and Prasad IR: Enhancement of Solubility and Dissolution rate of ezetimibe through liquisolid technique. Int. J. Pharm. Sci.Res. 2010, 5(2): 50-60.

10. SanjeevRaghavendraGubbi and Ravindra Jarag.Formulation and Characterization of Atorvastatin Calcium Liquisolid Compacts.Asian J. Pharm. Sci.5(2); 50-60, 2010.

11. Yu, L. X.; Amidon, G. L.; Polli, J. E.; Zhao, H.; Mehta, M. U.; Conner, D. P.; Shah, V. P.; Lesko, L. J.; Chen, M. L.; Lee, V. H. L. Biopharmaceutics classification system: The scientific basis for biowaiver extensions. Pharm. Res. 19(7); 921-925; 2002.
12. Lindenberg, M.; Kopp, S.; Dressman, J. B. Classification of orally administered drugs on the World Health Organization model list of essential medicines according to the Biopharmaceutics classification system. Eur. J. Pharm. Biopharm. 58; 265-278; 2004.

13. Varma, M. V.; Khandavilli, S.; Ashokraj, Y.; Dhanikula, A.; Sood, A.; Thomas, N. S.; Pillai, O.; Sharma, P.; Gandhi, R.; Agrawal, S.; Nair, V.; Panchagnula, R. Biopharmaceutics classification system: A scientific framework for pharmacokinetic optimization in drug research. Curr. Drug Metab. 5(5); 375-388; 2004.

14. Nyol Sandeep and M.M. Gupta. Immediate Drug Release Dosage Form: A Review.

15. L. Lachman, H. Lieberman, and J. L. Kanig, The Theory And Practise of Industrial Pharmacy, Lea \& Febiger, 3rd edition,1986.

16. M. Clugston and R. Fleming, Advanced Chemistry, Oxford Publishing, Oxford, UK, 1st edition, 2000.

\section{How to cite this article:}

Bhagya Sree et al., Formulation and evaluation of liquisolid compacts of aceclofenac. Int. J. Adv. Pharm. Biotech., 2017; 3(3): 1-13. 